\title{
State of the art in advanced endoscopic imaging for the detection and evaluation of dysplasia and early cancer of the gastrointestinal tract
}

\author{
Sergio Coda ${ }^{1,2}$ \\ Andrew $\vee$ Thillainayagam ${ }^{1,2}$ \\ 'Section of Gastroenterology and \\ Hepatology, Department of Medicine \\ and Photonics Group, Department \\ of Physics, Imperial College London, \\ London, UK; '²ndoscopy Unit, Charing \\ Cross Hospital, Imperial College \\ Healthcare NHS Trust, London, UK
}

Video abstract

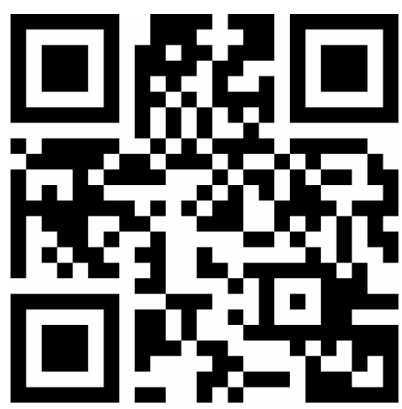

Point your SmartPhone at the code above. If you have a QR code reader the video abstract will appear. Or use: http://dvpr.es/ImQnsxI

This article was published in the following Dove Press journal:

Clinical and Experimental Gastroenterology

13 May 2014

Number of times this article has been viewed

\begin{abstract}
Ideally, endoscopists should be able to detect, characterize, and confirm the nature of a lesion at the bedside, minimizing uncertainties and targeting biopsies and resections only where necessary. However, under conventional white-light inspection - at present, the sole established technique available to most of humanity - premalignant conditions and early cancers can frequently escape detection. In recent years, a range of innovative techniques have entered the endoscopic arena due to their ability to enhance the contrast of diseased tissue regions beyond what is inherently possible with standard white-light endoscopy equipment. The aim of this review is to provide an overview of the state-of-the-art advanced endoscopic imaging techniques available for clinical use that are impacting the way precancerous and neoplastic lesions of the gastrointestinal tract are currently detected and characterized at endoscopy. The basic instrumentation and the physics behind each method, followed by the most influential clinical experience, are described. High-definition endoscopy, with or without optical magnification, has contributed to higher detection rates compared with white-light endoscopy alone and has now replaced ordinary equipment in daily practice. Contrast-enhancement techniques, whether dye-based or computed, have been combined with white-light endoscopy to further improve its accuracy, but histology is still required to clarify the diagnosis. Optical microscopy techniques such as confocal laser endomicroscopy and endocytoscopy enable in vivo histology during endoscopy; however, although of invaluable assistance for tissue characterization, they have not yet made transition between research and clinical use. It is still unknown which approach or combination of techniques offers the best potential. The optimal method will entail the ability to survey wide areas of tissue in concert with the ability to obtain the degree of detailed information provided by microscopic techniques. In this respect, the challenging combination of autofluorescence imaging and confocal endomicroscopy seems promising, and further research is awaited.
\end{abstract}

Keywords: image-enhanced endoscopy, narrowband imaging, autofluorescence imaging, confocal laser endomicroscopy, fluorescence lifetime imaging

\section{Introduction}

Cancer of the gastrointestinal (GI) tract is the leading cause of cancer death worldwide. ${ }^{1}$ Prevention is based on early endoscopic detection of potentially curable cancers or precursor conditions such as dysplasia, which have a significant risk of progression to malignancy. ${ }^{2}$ Thus, early diagnosis is the critical goal, since it allows endoscopic or surgical intervention on a localized disease without lymph node involvement, which greatly improves patient survival.

However, easy and accurate detection of dysplasia, early detection of malignancies and accurate discrimination of inflammatory disease from neoplasia remain the main chal-

Correspondence: Sergio Coda Room 629, Level 6, Blackett Laboratory, Imperial College London, Prince Consort Road, London SW7 2AZ, UK

Tel +44 2075947738

Fax +4420759477/4

Email s.coda@imperial.ac.uk 
lenges in GI endoscopy. There are at least four main domains where the clinical needs are still unmet. For instance, in Barrett's esophagus (BE), up to $40 \%$ of high-grade dysplasia (HGD) was found to be associated with inconspicuous synchronous occult foci of adenocarcinoma after esophagectomy. ${ }^{3,4}$ Standard whitelight endoscopy (WLE) identifies BE and obvious mucosal abnormalities (eg, nodules, and raised and depressed areas) but cannot distinguish intestinal metaplasia from dysplasia or other types of metaplasia (cardiac or oxyntic) not at risk of malignancy. Moreover, the current standard method for detecting dysplasia in patients with $\mathrm{BE}$ is a random four-quadrant biopsy protocol (Seattle protocol), but dysplasia can easily be missed, as only a small fraction of the Barrett's segment (less than 3.5\% of the total surface of a $2 \mathrm{~cm}$ long segment) is sampled. ${ }^{5}$

Detection of early gastric cancer is still a gray area in clinical endoscopy due to the minute changes such as faint mucosal irregularities or discoloration, which can be easily overlooked. For instance, apart from Japan, only 10\% of gastric cancers are detected at an early stage in most of the world. ${ }^{6}$ Although chromoendoscopy is increasingly employed, the identification of early cancer remains poor unless an obvious abnormality such as an ulcer or mass is found.

Adenoma miss rates of up to $25 \%$ during colonoscopy have been reported. ${ }^{7-9}$ Interval cancers have also been found in patients with a history of adenomatous polyps, despite regular colonoscopy surveillance. ${ }^{10,11}$ Adenomas usually originate as diminutive polyps. However, only two-thirds of colorectal cancer (CRC) seems to develop through the stage of adenoma, the other third growing de novo from normal epithelium. ${ }^{12}$ Aberrant crypt foci, defined as colonic crypts with a larger diameter and a thicker epithelium than normal mucosa, have been proposed as one of the earliest stages of malignant transformation. However, these changes are too subtle to be visualized with a standard endoscope. ${ }^{13}$ Similarly, detection of flat polyps, which are characterized by a high malignant potential compared with sessile and pedunculated polyps, ${ }^{14,15}$ can be extremely difficult because of the less well-defined subtle findings.

Lastly, dysplasia and malignant transformation represent the most important complication in patients with inflammatory bowel disease (IBD). At present, annual endoscopic surveillance is recommended after 8-10 years of disease. In patients with ulcerative colitis, if no lesions are observed, four biopsy specimens are taken randomly at every $10 \mathrm{~cm}$ between the rectum and the cecum for a total of 40-50 biopsies per colonoscopy. ${ }^{16}$ However, even this massive sampling regimen examines less than $1 \%$ of the total colonic mucosa surface. In addition, the natural history of dysplasia in the context of IBD is poorly understood. Dysplasia in IBD can be flat (endoscopically invisible) or elevated (endoscopically detectable). ${ }^{17}$ Elevated lesions are referred to as dysplasia-associated lesions or masses (DALMs) and are broadly separated into adenoma-like and non-adenoma-like depending on whether or not they resemble sporadic adenomas unrelated to IBD. It is still unclear whether all elevated dysplastic lesions begin as flat endoscopically invisible dysplasia, and it is extremely difficult, if not impossible, to discriminate dysplasia from regenerative or inflammatory changes, both in presence or absence of a visible lesion (ie, pseudopolyps, DALM, and raised or depressed areas of mucosa). Another major problem during surveillance for cancer in patients with IBD is the histological finding of dysplasia in random biopsies of diffusely inflamed mucosa as well as of macroscopically normal mucosa, and not in those targeted to a visible lesion. ${ }^{17}$

In recent years, a range of innovative techniques have been developed and adapted for clinical endoscopy with the aim of addressing these unmet clinical needs, providing a "red flag" technique, and perhaps ultimately revealing lesions that are still invisible under conventional WLE. Some of these methods enhance and optimize the inherent contrast available, while others offer the possibility of assessing the tissue structure in real-time at a microscopic level.

Commercially available techniques include high-definition endoscopy (HDE), ${ }^{18-20}$ magnifying chromoendoscopy, ${ }^{21}$ narrow-band imaging (NBI), ${ }^{22}$ Fuji intelligent chromoendoscopy (FICE), ${ }^{23}$ i-Scan (Pentax; Hoya Corporation, Tokyo, Japan), ${ }^{24}$ autofluorescence imaging (AFI), ${ }^{25}$ confocal laser endomicroscopy (CLE), whether by integrated technology (endoscope-based CLE [eCLE] $)^{26}$ or through-the-scope probe-based CLE (pCLE), ${ }^{27}$ and endocytoscopy (EC). ${ }^{28}$ Among these techniques, endoscopic confocal microscopy has gained prominence since 2004, when the first in vivo study appeared on the clinical scene. ${ }^{26}$ For clinical applications in gastroenterology, pCLE, an evolution and miniaturization of CLE, was subsequently launched in $2007,,^{27,29}$ and highly promising results have been reported since then. ${ }^{27,30-34}$ Many other potential applications are yet to be validated, and research to make CLE "label-free" is currently in progress. ${ }^{35}$

A consensus methodological classification of endoscopic imaging proposed by Tajiri and $\mathrm{Niwa}^{36}$ in 2008 divides the existing techniques into five major categories: 1) conventional (WLE); 2) image-enhancement (further subdivided into digital, optical-digital, and chromoendoscopy methods); 3) magnifying (optical and digital); 4) microscopic (CLE and EC); and 5) tomographic (endoscopic ultrasonography and optical coherence tomography). Figure 1 provides an 


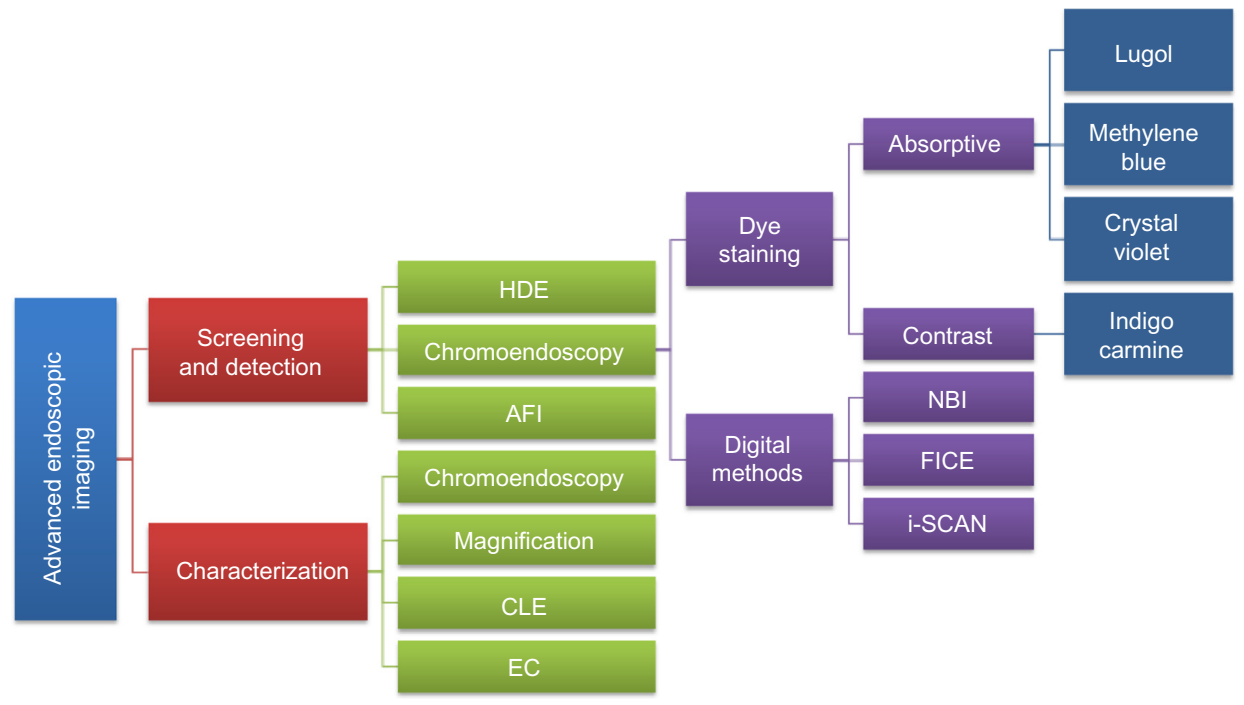

Figure I Goal-oriented classification of image-enhancement, magnifying, and microscopic techniques currently available and approved for clinical use. Note: i-Scan is manufactured by Pentax.

Abbreviations: AFI, autofluorescence imaging; CLE, confocal laser endomicroscopy; EC, endocytoscopy; FICE, Fuji intelligent chromoendoscopy; HDE, high-definition endoscopy; NBI, narrow-band imaging.

overview together with a goal-oriented classification of the currently available image-enhancement, magnifying, and microscopic techniques (categories 2, 3, and 4, respectively) approved for clinical use in GI endoscopy.

This review is based on a comprehensive MEDLINE ${ }^{\circledR}$ search of studies published since 1995, using the terms "dysplasia," "early gastrointestinal cancer," "magnification," "high definition endoscopy (HDE)," "narrow band imaging (NBI)," "autofluorescence imaging (AFI)," "Fuji intelligent chromoendoscopy (FICE)," "i-Scan," "confocal laser endomicroscopy (CLE)," and "endocytoscopy (EC)." Only extensively referenced studies describing the use of clinically approved commercially available techniques, as defined by the Tajiri and Niwa classification of endoscopic imaging, ${ }^{36}$ and investigating the detection/evaluation of GI dysplasia and early cancers, were included. Both authors contributed equally to the search and selection of the studies, design of the review, discussion and interpretation of results, and critical revision, also reflecting personal experience and expert opinions. The aim of this review is to provide a concise and comprehensive synopsis of the latest advanced imaging techniques that are impacting the way precancerous and neoplastic lesions of the GI tract are currently detected and characterized at endoscopy. It embraces both: 1) evaluation of all available modalities, those in day-to-day use as well as those under experiment; and 2) identification of directions for future investigation/research. For each technique, the fundamental principles and instrument specifications are summarized as well as their clinical application and potential roles as tools for the endoscopist. Particular emphasis is given to the currently available techniques that are still research based (eg, AFI and CLE) and need consolidation, rather than to those closer and already implemented in the clinical practice (eg, HDE, chromoendoscopy, and virtual chromoendoscopy). One role envisaged is a "red flag" guide to potential areas of malignancy, reducing time and the number of diagnostic biopsies taken. In this respect, the potential combination of current techniques as well as the integration of future potential clinical optical imaging modalities, such as fluorescence lifetime imaging microscopy (FLIM), is anticipated. This information may help guide future studies in this field and assist in developing more accurate, lower cost, and faster instrumentation.

\section{HDE, chromoendoscopy, and magnification endoscopy}

As in modern television technology, high-definition video endoscopes utilize charge-coupled devices (CCDs) with over a million pixels compared with older CCDs with an average of 300,000 .

Magnifying endoscopes have a lens system built into the distal tip of the instrument. This zoom can be used to magnify areas of GI mucosa from $\times 6$ to $\times 150$. The main difficulty when using this endoscope is to keep the instrument still and maintain the interface between tissue and tip of the instrument constant for accurate focusing. Particularly in upper GI endoscopy, breathing and peristalsis require continuous adjustments. 
Magnification is often combined with the use of vital dyes (chromoendoscopy) to enhance the contrast in the surface (Figure 2).

\section{Clinical experience Upper Gl tract}

Lugol's vital staining is the most commonly used method to enhance the detection of esophageal squamous dysplasia and early squamous cell carcinoma in high-risk populations, and variable sensitivity $(91 \%-100 \%)$ and specificity (40\%-95\%) have been reported. ${ }^{37-39}$

In BE, methylene blue is undoubtedly the preferred dye to enhance the detection of dysplasia and early cancer, although its value is still controversial due to the reported wide range of sensitivities (32\%-98\%) and specificities (23\%-100\%), ${ }^{40}$ high level of interobserver variability, ${ }^{41}$ and inconsistent rates of increased detection. ${ }^{42-46}$

Using magnifying endoscopy and methylene blue, Endo et $\mathrm{al}^{47}$ proposed a classification of five esophageal pit patterns to distinguish metaplastic epithelium from gastric phenotypes. Based on correlation with histology and mucin phenotypes, types 4 and 5 were found to be highly related to the presence of intestinal metaplasia.

Clinical experience with other staining methods in BE remains limited, and their role has not yet been established. Among others, use of indigo carmine in combination with
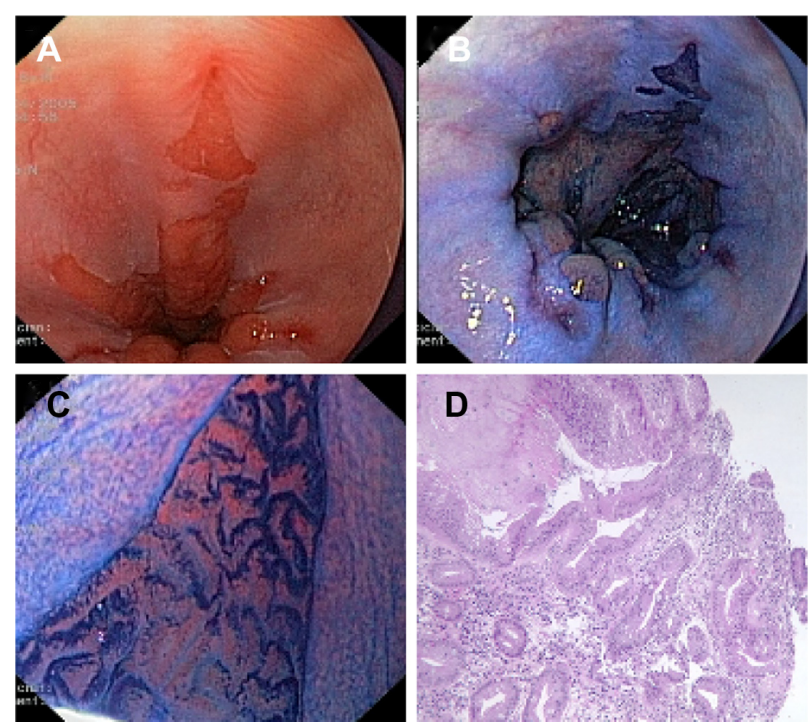

Figure 2 (A) Conventional endoscopic view of Barrett's esophagus with concomitant esophagitis. (B) Positive staining of Barrett's epithelium after absorption chromoendoscopy with methylene blue dye solution $(1 \%, 10 \mathrm{~mL})$. (C) Villous cerebroid pits with finger-like projections seen with magnification endoscopy (pattern 5 according to Endo's classification). (D) Histological section of (C) showing intestinal metaplasia with glands of different size and shape and numerous goblet cells.

Note: Images provided courtesy of Dr Sergio Coda and Professor Paolo Trentino, University of Rome "La Sapienza," Italy. enhanced magnification endoscopy has been found useful in distinguishing non-dysplastic from dysplastic pit patterns. $^{48}$

Four different mucosal pit patterns were identified using magnifying endoscopy with acetic acid in patients with short-segment BE without dysplasia. In this study, types 3 and 4 were shown to contain intestinal metaplasia in $87 \%$ and $100 \%$, respectively, of biopsy specimens. ${ }^{49}$

Methylene blue staining with magnifying endoscopy has also been applied to detect gastric intestinal metaplasia and dysplasia with $84 \%$ and $83 \%$ accuracy, respectively. In this study, specific mucosal patterns were identified and classified into three groups: 1) non-metaplastic, non-dysplastic mucosa; 2) metaplastic mucosa; and 3) dysplastic mucosa ${ }^{50}$ However, in some cases, it is practically difficult to achieve reliable and clear pattern identification (and interobserver agreement) due to uneven spreading of the dye and heterogeneous staining of the gastric mucosa.

\section{Lower GI tract}

By using magnifying endoscopes and indigo-carmine dye spraying, Kudo et $\mathrm{a}^{21}$ proposed a classification of five different polyp pit patterns associated with a percentage of correlation with the histology. This classification was meant to predict an increasing risk of neoplastic changes and assist clinicians in their therapeutic strategy planning. Kato et al, ${ }^{51}$ in one of the largest studies comparing these pit patterns with histology (3,438 lesions) found an accuracy of $75 \%$ for non-neoplastic lesions, $94 \%$ for adenomas, and $85 \%$ for carcinomas.

Chromoendoscopy is gaining more importance, as some of the colon cancers may not develop via the classical sequence adenoma-cancer but have only the transient phase of a small flat adenoma (de novo sequence). ${ }^{52}$

In a multicenter trial with 1,000 colonoscopies, the number of adenomas detected was almost $40 \%$ higher with the combination of magnification and chromoendoscopy compared with standard colonoscopy. ${ }^{53}$

In contrast, in another large multicenter study from France including 203 patients, no difference was found in the overall adenoma detection rate between standard-resolution ( $\leq 410,000$ pixels) WLE and high-resolution $(850,000$ pixels) WLE coupled with pan-colonic chromoendoscopy with indigo carmine (49.5\% versus 59.4\%, respectively). However, interestingly, high-resolution chromoendoscopy yielded a higher number of hyperplastic polyps and flat adenomas $<5 \mathrm{~mm}$ than pan-colonic chromoendoscopy with indigo carmine. ${ }^{54}$ 
HDE, with or without optical magnification, has now replaced ordinary equipment in daily practice, and its combination with dye staining is expected to become the standard of care for selected patients who need surveillance (eg, CRC, IBD, and BE). However, many aspects of this technique still need to be standardized (eg, the amount of dye to spray, the use of a spraying catheter, the power to be applied when spraying, which in turn determines the more or less homogeneous coloration of the target area). Nonetheless, although the effectiveness of chromoendoscopy has been shown, ${ }^{55,56}$ staining of the entire colon remains a time-consuming procedure.

\section{Virtual chromoendoscopy $\mathrm{NBI}$}

NBI (Olympus Corporation, Tokyo, Japan) is a digital filter technique that improves the visibility of capillaries, veins, and other subtle tissue structures by optimizing the absorbance and scattering of light without the use of contrast or absorptive dyes. Example images of NBI in comparison with conventional WLE are shown in Figure 3.

This system adapts the conventional additive RGB (red, green, and blue) color model of a conventional electronic endoscope with an ordinary light source (Figure 4A) and through the application of narrow-band filters to enhance the tissue microvascular architecture (Figure 4B).
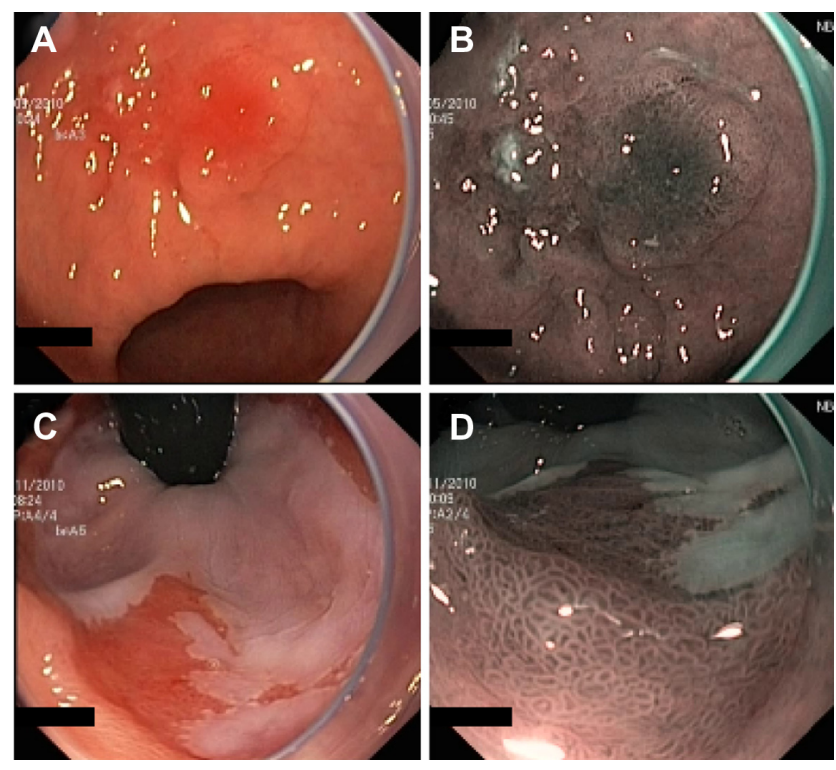

Figure 3 Example images of areas of suspected early cancers of the gastric antrum (A and $\mathbf{B}$ ) and cardia (C and D), imaged using standard WLE ( $\mathbf{A}$ and $\mathbf{C})$ and NBI (B and $\mathbf{D})$ to demonstrate the contrast enhancement provided by NBI.

Note: Images provided courtesy of Professor Paolo Trentino, University of Rome "La Sapienza," Italy.

Abbreviations: NBI, narrow-band imaging; WLE, white-light endoscopy.
NBI uses two bands of light, at $415 \mathrm{~nm}$ (blue) and at $540 \mathrm{~nm}$ (green). Narrow-band blue light preferably displays superficial capillary networks, while green light selectively displays deeper subepithelial vessels, and when combined, they offer an extremely high contrast image of the tissue surface. Commercial NBI systems apply image processing so as to display capillaries on the surface in brown, and veins in the subsurface in cyan.

NBI is based upon the phenomenon that incident light with longer wavelength undergoes less scattering and thus penetrates further into the tissue. Blue light penetrates only superficially, whereas red light penetrates into deeper layers. The choice of the two bands of light at 415 and $540 \mathrm{~nm}$ is determined by the peaks of absorption of hemoglobin (maxima at 415, 542, and $577 \mathrm{~nm}$ for oxyhemoglobin, and at 430 and $555 \mathrm{~nm}$ for deoxyhemoglobin ${ }^{57}$ (see inset of Figure $4 \mathrm{~B}$ ), thus the centered wavelengths resulting from the narrow-band filtering lead to a higher contrast for vascular structures.

The first prototype of the NBI system was developed by Gono et al in Japan. ${ }^{22,58}$ White light from a xenon lamp is conveyed through a rotary RGB filter that separates the white light into the colors red, green, and blue, which are used to sequentially illuminate the mucosa via the illumination channel of the endoscope (Figure 4). The red, green, and blue reflected light is detected sequentially by a monochromatic CCD placed at the tip of the endoscope, and the three images are integrated into a single color image by the video processor. In addition to the conventional RGB filters for WLE, the NBI system has filters of which the band-pass ranges have been narrowed and the relative contribution of blue light has been increased.

Compared with chromoendoscopy, NBI offers the advantage of providing contrast without the use of dyes, but the general endoscopists' confidence with this system is still under debate. One aspect of NBI is that images are less bright than those of WLE; therefore, it is often difficult to observe large areas from a distant view as the image quality significantly degrades with distance. This makes it more suited to detailed mucosal inspection rather than screening.

\section{Clinical experience}

Various studies have reported on the usefulness of NBI for enhanced detection of dysplasia and neoplasia, both in the upper and in the lower GI tract. The results are inconsistent and suggest that the clinical utility of NBI in day-to-day practice is limited. 


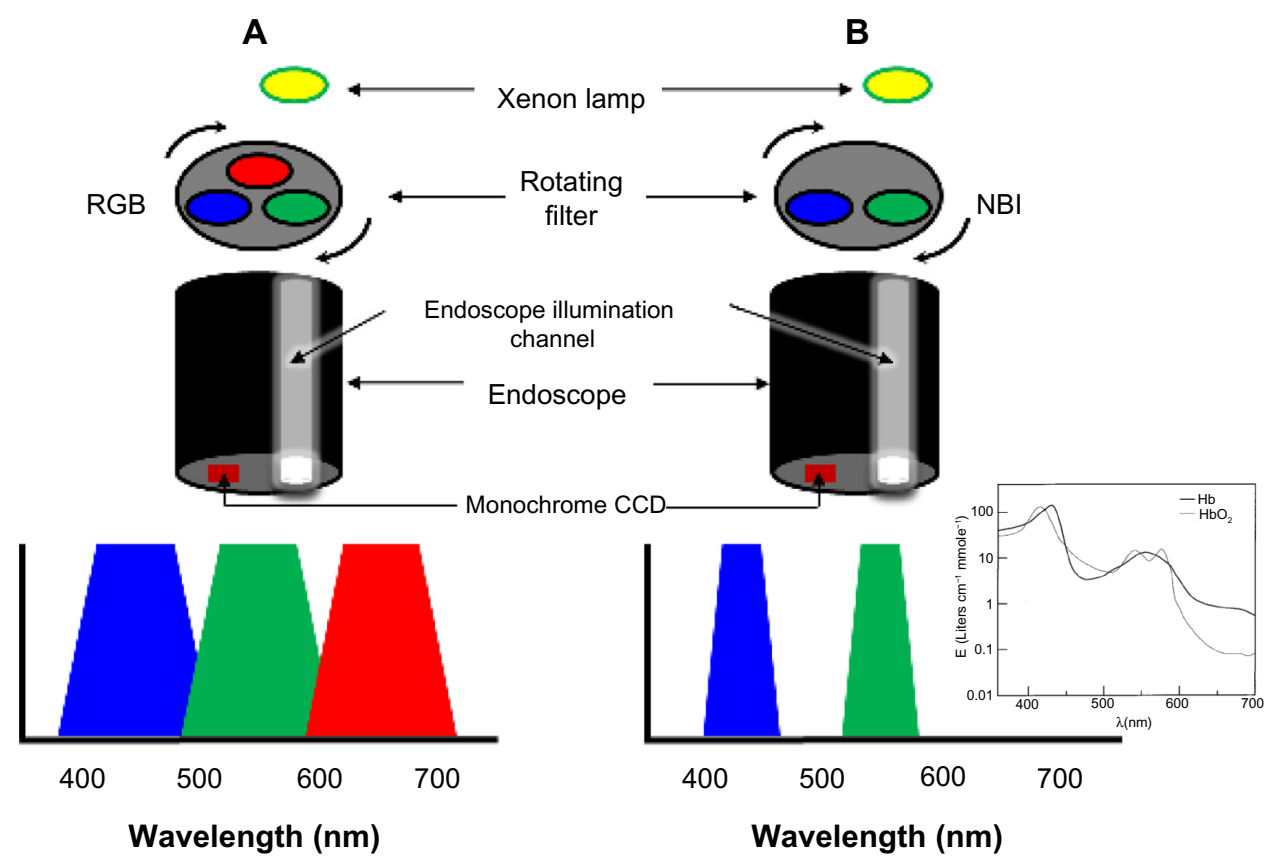

Figure 4 Schematic diagram showing the difference between a standard RGB filter (A) and the NBI filter (B).

Notes: Compared with the full range of white-light illumination, the filtered light penetrates the tissue less, highlighting the superficial details of the mucosa. Additionally, the filtered centered wavelengths fall within hemoglobin absorption bands (inset of $\mathbf{B}$ ), and this leads to a higher contrast for vascular structures. The inset of B is reproduced from Zonios G, Perelman LT, Backman V, Manoharan R, Fitzmaurice M, Van Dam J, Feld MS. Diffuse reflectance spectroscopy of human adenomatous colon polyps in vivo. Appl Opt. 1999;38(3I):6628-6637..$^{57}$ Copyright (C) 1999 Optical Society of America.

Abbreviations: CCD, charge-coupled device; NBI, narrow-band imaging; RGB, red, green, and blue.

\section{Upper Gl tract}

NBI as an adjunct technique to HDE, has shown a comparable performance to chromoendoscopy when applied in a randomized cross-over study of 28 patients with BE, and does not improve the overall sensitivity for identifying patients with HGD or early cancer. ${ }^{59}$ In a study with 56 patients with BE undergoing endoscopic surveillance for previously detected dysplasia, NBI detected significantly more dysplasia, and with recourse to fewer targeted biopsies, compared with WLE alone. ${ }^{60}$

In a recent study by Sharma et $\mathrm{al}^{61}$ in 123 patients with $\mathrm{BE}$ with mean circumferential and maximal extents of 1.8 and $3.6 \mathrm{~cm}$, respectively, NBI revealed more areas of dysplasia in patients with fewer biopsies when compared with HDE plus Seattle protocol.

\section{Lower Gl tract}

Early prospective comparative studies have reported higher diagnostic accuracies than WLE in distinguishing neoplastic from non-neoplastic polyps based on vascular and pit pattern characteristics. However, three randomized controlled trials failed to show an increased adenoma detection rate when comparing NBI with WLE. ${ }^{18,62}$

The vascular pattern intensity, a measure of microvascular density, was proposed by East et $\mathrm{l}^{63,64}$ as a new classification parameter to discriminate neoplastic from non-neoplastic polyps with NBI.

In a study of 62 patients with hereditary nonpolyposis $\mathrm{CRC}$, the adenoma detection rate was almost doubled when a second inspection with NBI was performed compared with standard colonoscopy alone. ${ }^{65}$

Using microvascular networks as a marker of neoplasia in a variety of organs including colon, esophagus, and lungs, a meta-analysis of eleven studies comparing NBI-based diagnoses of neoplasia with histopathology revealed a high diagnostic precision for detection of neoplasia, with an overall sensitivity and specificity of $94 \%$ and $83 \%$, respectively. ${ }^{66}$ In contrast, other studies have failed to demonstrate an improved detection of neoplastic polyps ${ }^{18,19,62}$ and dysplasia in patients with longstanding ulcerative colitis. ${ }^{67}$

Nowadays, the NICE (NBI international colorectal endoscopic) classification is the most extensively validated classification used worldwide, by which colorectal tumors can be simply classified, with or without magnification, into three types based on the color of the lesion, the microvascular architecture, and the surface pattern. Type 1 lesions are considered hyperplastic. Type 2 lesions include all adenomas (with low-grade dysplasia or HGD), carcinomas-in-situ or intramucosal carcinomas, and some 
lesions with superficial submucosal invasion. Invasive carcinomas with deep submucosal invasion have type 3 appearance. ${ }^{68}$

\section{FICE and i-Scan}

Along with NBI, the most recent development in virtual chromoendoscopy is the computed post-processing spectral estimation technology invented by Miyake et $\mathrm{al}^{69,70}$ and introduced with the FICE system by Fujinon Corporation (Saitama, Japan). A similar system was released in April 2007 by Pentax Corporation, the so called i-Scan technology.

In contrast to NBI, where the illumination light is filtered to achieve contrast, in FICE and i-Scan the contrast is obtained after the illumination has reached the tissue by processing the spectral reflectance captured by the CCD.

The FICE system is based on computed spectral estimation of photons reflected from an ordinary white-light image. In this way, white-light images are sent to a spectral estimation matrix processing circuit and reconstructed in three distinct virtual single-wavelength images: red, green, and blue. By combining these three single wavelength images, a resultant FICE-enhanced color image is then obtained.

i-Scan technology is based on digital filter enhancement and software manipulation of color tone, sharpness, and contrast of high-definition images (1.25 million pixels). i-Scan can be used in three modes depending on the level of enhancement desired: 1) surface enhancement for easier demarcation of edges and flat lesions by enhancing light-todark contrast; 2) contrast enhancement for better identification of depressed lesions by enhancing areas of low intensity; and 3) tone enhancement for improved mucosal structure assessment by increasing the illumination and emphasis on vascular features.

\section{Clinical experience}

In patients with BE complicated by suspected HGD or early cancer, FICE shows similar sensitivity to acetic acid chromoendoscopy ( $87 \%$ for both techniques on a "per lesion" basis, and $92 \%$ versus $83 \%$ on a "per patient" analysis for FICE and chromoendoscopy, respectively). ${ }^{71}$ An increase in sensitivity is observed by combining targeted biopsies plus standard four-quadrant random biopsies (88\% and $96 \%$ in the "per patient" analysis for FICE and chromoendoscopy, respectively).

When compared with WLE, transnasal FICE provides clearer delineation of the esophagogastric junction by identifying the palisade vessels - a reliable, but often invisible to
WLE, anatomical marker of esophageal origin for measuring the extension of Barrett mucosa with accuracy. ${ }^{72}$ However, detection of dysplasia is not attempted due to the limited field of view (FOV) of the endoscopes used.

In a study by Neumann et al, ${ }^{73}$ double-balloon enteroscopy-assisted FICE failed to improve the detection or delineation of ulcers and erosions in three patients with Crohn's disease but was found to be useful for the characterization of adenomatous polyps and angiodysplasias of the small bowel.

Hoffman et $\mathrm{al}^{24}$ reported a significantly increased detection rate of small $(\leq 5 \mathrm{~mm})$ adenomas for i-Scan when compared with WLE alone (11 versus 5 , respectively). The inspection was conducted in the last $30 \mathrm{~cm}$ of the colon during the withdrawal phase of colonoscopy. Interestingly, the same detection rate was found for both conventional chromoendoscopy with methylene blue and i-Scan, although chromoendoscopy was considerably more time-consuming than i-Scan (13 versus 5 minutes). In contrast, in a recent study by Basford et $\mathrm{al}^{74}$ involving 209 polyps in 84 patients, no significant differences between HDE and i-Scan were observed in overall diagnostic accuracy of polyps $<10 \mathrm{~mm}$ (93.3\% versus $94.7 \%)$.

\section{$\mathrm{AFI}$}

AFI is a technique based on the principle that excitation of tissue with specific wavelength (eg, in the blue) leads to emission of a longer wavelength of light. In the GI tract, AFI detects subtle changes in the concentration of specific chemicals in tissue that have the ability to fluoresce when excited (endogenous fluorophores). Malignant transformation is associated with emission of relatively longer wavelengths of light (shift from green toward the red end of the spectrum).

Currently, the only commercially available AFI devices are RGB-based video endoscopes with trimodal (WLE + $\mathrm{NBI}+\mathrm{AFI}$ ) capability (Evis Lucera Spectrum; Olympus Medical Systems Corp, Tokyo, Japan). Two separate monochromatic CCDs are located at the tip of these endoscopes. One CCD is for high-definition WLE and NBI, and the other $\mathrm{CCD}$ is specific for AFI.

In AFI mode, blue light (390-470 nm) and green light $(540-560 \mathrm{~nm})$ is sequentially generated by a xenon lamp and conveyed through a rotating color filter wheel. An interference filter situated proximally to the AFI CCD blocks the blue light excitation but allows tissue autofluorescence $(500-630 \mathrm{~nm})$ and reflected green light to pass through. ${ }^{75}$

The autofluorescence and green reflectance images are captured and integrated by the video processor into a 

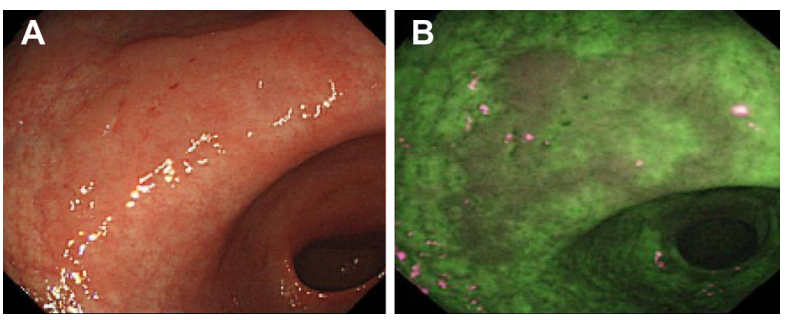

Figure 5 Example images of a suspected early cancer of the gastric antrum, imaged using standard WLE (A) and AFI (B), to demonstrate the contrast enhancement provided by AFI (Olympus Corporation, Tokyo, Japan).

Notes: Images provided courtesy of Dr Chizu Yokoi, National Center for Global Health and Medicine, Tokyo, Japan.

Abbreviations: AFI, autofluorescence imaging; WLE, white-light endoscopy.

single pseudocolor image, where normal mucosa typically appears green, and dysplastic or neoplastic tissue purple (Figure 5).

However, the reason for the difference in fluorescence between normal and diseased tissue observed in current commercial AFI systems is still unclear, and intensity-based contrast is often not sufficiently specific. ${ }^{75-77}$

\section{Clinical experience Upper Gl tract}

A large multicenter randomized trial with patients affected by BE compared the diagnostic accuracy of surveillance with AFI-targeted biopsies plus Seattle protocol in comparison with the conventional Seattle protocol only. The investigators suggested that the AFI-guided biopsies improved the diagnostic accuracy for neoplasia in comparison with the conventional approach when using four quadrant biopsies. However, because of decreased sensitivity, they concluded that AFI alone was not suitable for replacing the standard Seattle protocol. ${ }^{78}$

More recently, AFI with blue-light excitation has been combined with high-definition WLE and NBI in a single endoscope with two CCDs. This technology is referred to as "trimodal imaging" and has been applied to identify inconspicuous Barrett's neoplasia ${ }^{79}$ and assist endoscopic mucosal resection (EMR) of early neoplasia in $\mathrm{BE} .{ }^{80} \mathrm{In}$ an international multicenter study involving 84 patients with $\mathrm{BE}$, the addition of AFI to high-resolution endoscopy increased the detection rate of early neoplasia within the Barrett segment, and additional viewing with NBI increased the overall specificity. ${ }^{79}$ However, as with AFI alone, the increased detection of dysplasia was only marginal (11\%) and did not translate into a real benefit for the patients. Moreover, AFI alone was associated with a high false-positive rate (81\%); therefore, the authors used NBI with optical magnification to further characterize areas detected by AFI, reducing the false-positive rate to $26 \%$ (at the expense of misclassifying two lesions as falsely negative).

Endoscopic molecular imaging using fluorescently labeled targeted peptides is being increasingly investigated for detection of inconspicuous dysplasia in BE. For example, glycans have been shown to be altered in GI cancers. ${ }^{81-84}$ Glycan changes can be detected using lectins, which have specific affinity for particular glycans. AFI and a fluorescently labeled lectin, wheat-germ (Tritium vulgar) agglutinin (WGA), have been used to detect changes in glycan expression on the epithelial cell surface associated with the transition from $\mathrm{BE}$ through dysplasia to adenocarcinoma ${ }^{85}$ In particular, AFI has been used to image WGA in four esophagectomy specimens obtained immediately after surgery. The specimens were intubated from the proximal end, and both baseline WLE and AFI images were acquired. Fluorescein-labeled WGA was sprayed over the esophageal mucosa and imaged with 395-475 nm excitation. Specimens were then opened along their vertical axis and imaged using an IVIS ${ }^{\circledR}$ camera (Caliper Life Sciences, Hopkinton, MA, USA) to enable quantification of fluorescence and registration with histology. A highly significant statistical correlation between WGA fluorescence and the degree of dysplasia was found $(P=0.0002)$, with areas of HGD and cancer showing lower fluorescence intensity and WGA binding relative to areas of non-dysplastic $\mathrm{BE}$ and normal esophageal mucosa.

Kim et a ${ }^{86}$ performed preoperative AFI in 20 patients with early gastric cancers and then compared the endoscopic characteristics with histology after endoscopic submucosal dissection. Categorization of AFI images of gastric cancers into four patterns proved to be useful to delineate the dissection margins in the majority of cases.

\section{Lower Gl tract}

A large body of literature exists on the use of autofluorescence to investigate colonic polyps and adenocarcinomas. Typically, colonic neoplasms have shown decreased autofluorescence intensity compared with that of normal colon. This can be attributed to the decrease with neoplasia of mucosal collagen, which is the dominant fluorophore, as a consequence of the enlargement of crypts that progressively displace the lamina propria. In addition, the submucosal contribution to the fluorescence in adenomatous tissue is reduced compared with that in normal colon due to the increased thickness of the polyp and absorption by hemoglobin, as a result of increased intra-tumoral microvessel density.

In a randomized trial on 100 patients undergoing screening colonoscopy, AFI was not able to significantly improve 
the diagnostic accuracy, with adenoma miss-rates similar to WLE. ${ }^{87}$

In a multicenter prospective randomized controlled study, the use of trimodal imaging did not improve the detection rate for adenomas compared with standard endoscopy. NBI and AFI showed very little accuracy and specificity in differentiating adenomas from non-adenomas (63\% and $75 \%$ versus $37 \%$ and $62 \%$, respectively). ${ }^{88}$ Also, differentiation of adenomas from hyperplastic polyps by using trimodal imaging in patients with hyperplastic polyposis was unsatisfactory. ${ }^{89}$

Another study from Japan showed that the florescence intensity of images acquired using an AFI system is inversely

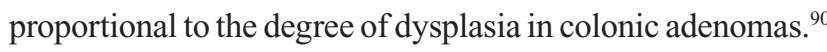
This study suggested that the dysplastic changes, including an increased number and density of cells and crypts, and the enlargement of nuclei and crypts, might somehow alter the tissue permeability and thus jeopardize the way back to the surface of the emitted fluorescence.

Since the assessment of AFI images is strictly dependent on color presented to the clinician by the image processing system used, quantifying the intensity of the color "magenta" by calculating a fluorescence index has been proposed as a method to discriminate lymphomas from reactive lymphoid hyperplasia, ${ }^{91}$ and to evaluate the degree of dysplasia in colonic neoplasms..$^{90}$

\section{CLE}

Confocal microscopy was invented by Minsky in the 1950 s. ${ }^{92,93}$ Since its conception and development, confocal microscopy has been extensively used in biology and medicine for imaging living intact tissues without having to physically cut up and prepare thin sections as in histology.
In confocal microscopy, the light source, the sample plane, and the detector are all confocal (ie, in conjugate image planes) (Figure 6). The illumination light is focused to a point in the sample, and all the fluorescence collected by the objective lens from that point is forced through a pinhole to reach the detector. Although other parts of the sample are also illuminated, light from out-of-focus planes in the sample is blocked by the pinhole and does not reach the detector. Thus, the main advantage of a confocal microscope is its optical sectioning ability, giving insight into the three-dimensional tissue structure and providing a virtual real-time histological diagnosis.

CLE is one of the newest advancements in diagnostic endoscopy and is a highly promising technique for investigating the mucosal surface together with its immediate subsurface areas. Cell structures and tissue morphological characteristics can be visualized to a maximum depth of $250 \mu \mathrm{m}$.

As mentioned above, two types of confocal endomicroscope have been developed: the confocal laser endomicroscope (eCLE) (Pentax Corporation), in which a miniaturized confocal scanner has been integrated into the distal tip of a conventional endoscope, and the probe-based system (pCLE) (Cellvizio ${ }^{\circledR}$; Mauna Kea Technology, France), which can be passed through the working channel of standard endoscopes and has an external laser scanning unit.

\section{eCLE}

The confocal laser endomicroscope is based on microelectro-mechanical system scanning mirror technology. The micro-electro-mechanical system scanning mirror oscillates to provide a scan pattern to the beam of light. A single-mode

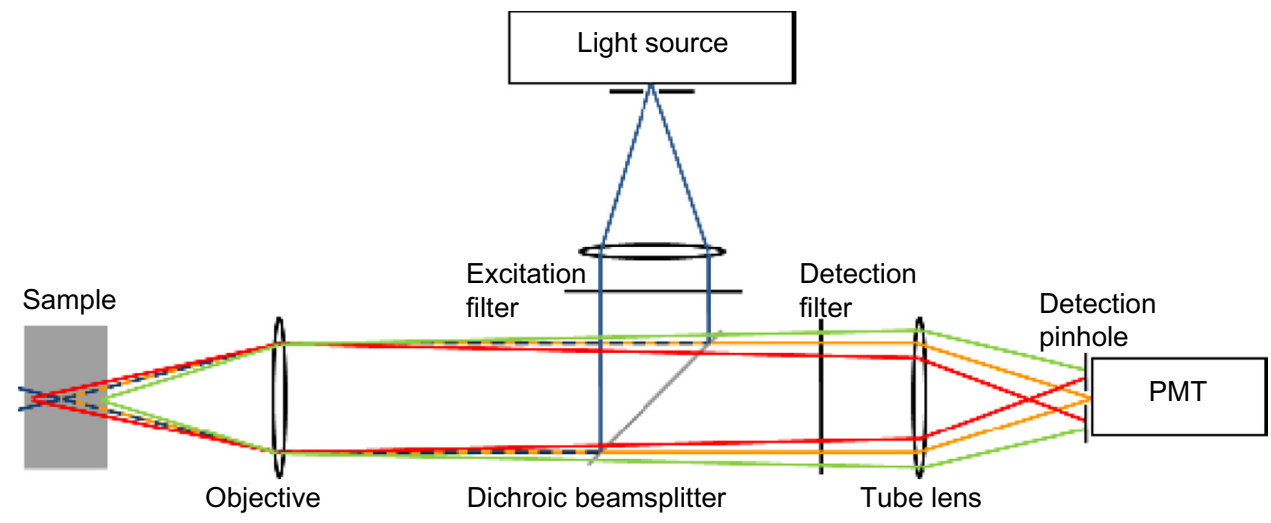

Figure 6 Schematic diagram of confocal microscopy principles.

Notes: The blue rays (pre- and post-objective and excitation filter) indicate the laser illumination delivered to the tissue sample. The fluorescence emitted from a tissue layer in focus (orange rays) will pass through the pinhole and will be detected. The majority of the fluorescence emitted from tissue layers out of focus (red and green rays) will be rejected. Illumination and collection therefore occur in the same focal plane (ie, they are confocal). Figure adapted with permission from Kumar S. Development of Multidimensional Fluorescence Imaging Technology with a View towards the Imaging of Signalling at the Immunological Synapse [doctoral thesis]. London: Chemical Biology Centre, Department of Chemistry, Imperial College London; 2010. ${ }^{151}$

Abbreviation: PMT, photomultiplier tube. 
(Gaussian beam profile) fiber, acting as both the illumination point source and the detection pinhole, and a miniature objective lens at the distal end of a conventional video endoscope (EG3870K, EC-3870CILK; Pentax, Hoya Corporation, Japan) enable confocal microscopy in addition to standard video endoscopy.

A blue laser integrated into the endoscope light source is coupled into a single-mode fiber that delivers an excitation wavelength of $488 \mathrm{~nm}$ to the sample, and fluorescence emitted by the sample is detected at wavelengths above $505 \mathrm{~nm}$. Viewing of a specific tissue depth is enabled by scanning successive points within the tissue in a grid of pixels along the $\mathrm{x}$ - and $\mathrm{y}$-axes (parallel to the tissue surface) to produce sections of $475 \mu \mathrm{m} \times 475 \mu \mathrm{m}$ (FOV) at variable imaging depths (range $0-250 \mu \mathrm{m}$ ). The lateral resolution is $0.7 \mu \mathrm{m}$, and the axial resolution is $7 \mu \mathrm{m}$. eCLE can produce conventional white-light endoscopic images and confocal images at the same time, with a pixel density of 1,024 pixels $\times 512$ pixels at an acquisition rate of 1.6 frames per second or 1,024 pixels $\times$ 1,024 pixels at 0.8 frames per second. ${ }^{94,95}$

The distal tip of the endoscope contains an air- and waterjet nozzle, two light guides, an accessory channel used for irrigation and topical application of the contrast agent, and a $2.8 \mathrm{~mm}$ operative channel. Actuation of imaging plane depth is controlled using two remote control switches located on the handle. ${ }^{26}$

\section{PCLE}

pCLE consists of a coherent single mode fiber bundle, a miniature microscope objective, and two scanning mirrors at the proximal end of the bundle. The bundle has an outer diameter of $2 \mathrm{~mm}$ and can be introduced through the working channel of most endoscopes. In pCLE, a laser is sequentially focused onto single fibers at the proximal end of the bundle. The light exiting the fiber at the distal end is focused to a point in the sample using a miniature objective. Confocal fluorescence is focused by the objective onto the same fiber in the bundle. The light is detected on a detector, and the beam is eventually scanned over all fibers in the bundle to build up an image. The lateral and axial resolution range from 2.5 to $5.0 \mu \mathrm{m}$ and from 15 to $20 \mu \mathrm{m}$, respectively. ${ }^{96}$ pCLE has a fixed image plane depth varying between 55 and $130 \mu \mathrm{m}$, depending on the probe used..$^{94}$

\section{Comparison of eCLE and pCLE}

The main advantage of eCLE over pCLE is that the imaging plane depth is user tunable because the laser scanner is integrated into the endoscope and allows optical sectioning of the tissue at higher axial resolution (lateral resolution $0.7 \mu \mathrm{m}$, axial resolution $7 \mu \mathrm{m}$ versus 2.5 and $15 \mu \mathrm{m}$, respectively), whereas in pCLE the imaging plane depth is fixed and cannot be adjusted..$^{95-97}$

In pCLE, the resolution is limited by the number of fibers $(30,000)$, but the image acquisition is faster than that of eCLE (12 versus 0.8-1.6 frames per second). One disadvantage of eCLE is the insertion tube diameter of the distal tip $(12.8 \mathrm{~mm})$ compared with the standard outer diameters of conventional endoscopes $(9.0-11.1 \mathrm{~mm})$. In contrast, pCLE, due to the small diameter of the bundle, permits the imaging of narrowed lumina such as the biliary and pancreatic ducts, ureters, and neoplastic or inflammatory strictures. Disadvantages of pCLE include limited lifespan (20 procedures), higher maintenance cost, ${ }^{95}$ and occupation of the endoscope working channel.

\section{Problems with current CLE systems}

A general drawback of the CLE technique is that intravenous (eg, fluorescein sodium) and topical (eg, acriflavine) fluorescence agents are used to achieve contrast. The avoidance of contrast agents would reduce both procedural time and any potential for associated adverse effects.

Fluorescein diffuses through the extracellular matrix of the epithelium and the lamina propria but does not stain cell nuclei. ${ }^{98}$ Acriflavine is a carcinogenic dye, ${ }^{99}$ and this clearly limits its clinical utility. ${ }^{95}$

Another drawback is the duration of the procedure, which can be almost twice as long as conventional endoscopy. In a study of contrast dynamics in porcine models, it has been reported that the best contrast and image quality can be achieved within the first 8 minutes after intravenous injection of $1 \%$ fluorescein, with highest signal-to-noise ratio (SNR) after 5 minutes. The SNR decreases significantly after 8 minutes. ${ }^{100}$ Furthermore, confocal endomicroscopy does not yet provide functional information about the tissue and is an examinerdependent technique. Interobserver and intraobserver variability has not been adequately studied, ${ }^{101}$ and the interpretation of the intensity images is often somewhat challenging among users, who may require substantial supplementary training in histology or the presence of the pathologist in the endoscopy room to achieve acceptable diagnostic accuracy. ${ }^{102,103}$

\section{Clinical experience with eCLE Upper Gl tract}

Kiesslich et al ${ }^{104}$ proved that the overall accuracy for eCLE in predicting $\mathrm{BE}$ and associated neoplasia was $96.8 \%$ and $97.4 \%$, respectively. 


\section{Lower Gl tract}

In 2004, Kiesslich et $\mathrm{al}^{26}$ showed that colonic dysplasia is detected using eCLE, with a sensitivity of $97.4 \%$ and a specificity of $99.4 \%$. Detection by eCLE of dysplasia in Peutz-Jeghers syndrome has also been reported. ${ }^{105}$

The potential of eCLE to differentiate colorectal lesions was recently demonstrated by Sanduleanu et al. ${ }^{106}$ In this study, low-grade dysplasia was distinguished from HGD with high accuracy (96.7\%), and eCLE predicted the final histology for all cases, with $95.7 \%$ accuracy.

\section{Clinical experience with PCLE Upper GI tract}

In a prospective, double-blind review of 20 pCLE images of 40 sites of $\mathrm{BE}$ tissue by using matching biopsies as the reference standard, the preliminary evaluation accuracy and interobserver agreement of pCLE was assessed among eleven experts in BE imaging from four different endoscopy centers from the United States and Europe. ${ }^{30}$ Although the study was limited by the small sample size, high preliminary accuracy in diagnosis of BE dysplasia and neoplasia was achieved, with both inexperienced (90\%) and experienced observers $(95 \%)$. The main strength of the present study relative to other published data is the inclusion of a large group of endoscopists, only four of whom had previous experience with pCLE. Their high performance demonstrated that rapid training in image interpretation is feasible.

The first international multicenter, randomized, controlled trial using pCLE in 101 patients with BE was published in 2011. The sensitivity and specificity of pCLE in addition to HDE was compared with HDE alone for the detection of HGD and adenocarcinoma. ${ }^{32}$ Use of pCLE with HDE showed increased "per-location" sensitivity for the detection of both conditions compared with HDE alone (68.3\% versus $34.2 \%$ ). Instead, 'per-location' specificity was slightly reduced $(87.8 \%$ versus $92.7 \%$ ). Nevertheless, no statistically significant differences in "per-patient" sensitivity were observed between HDE, NBI, or pCLE. However, a high negative predictive value was collectively observed, and authors speculated that pCLE might facilitate early rule-out of dysplasia with high degree of confidence, allowing better informed decisions to be made for the management and subsequent treatment of patients with $\mathrm{BE}$.

In a study by Bajbouj et al, ${ }^{31}$ optical biopsy with pCLE was compared with standard biopsy in the endoscopic evaluation of 68 patients ( 670 pairs of biopsies) with BE. Confocal images were interpreted live during examination as well as in a blinded controlled manner 3 months post-endoscopy, and findings compared with histology. pCLE was found to be comparable to endoscopic biopsy in excluding neoplasia, but due to its low positive predictive value and sensitivity, authors concluded that pCLE may currently not replace the standard practice for the diagnosis of BE-associated neoplasia.

\section{Biliary and pancreatic ducts}

Current techniques to detect malignant biliary and pancreatic strictures are of low sensitivity. The delay in tissue confirmation of malignancy can place a patient at risk for progression of disease precluding surgical resection. On the other hand, the inability to confirm whether a stricture is benign or malignant could lead to unnecessary surgery.

In 2008, Meining et al $^{107}$ used pCLE to examine the biliary tract of 14 patients with biliary strictures at the liver hilus or the common bile duct. Patterns indicative of neoplasia were identified, and pCLE predicted neoplasia with an overall accuracy of $86 \%$, surprisingly outperforming preoperative tissue sampling (79\%). After surgery, histopathology revealed invasive adenocarcinoma in two patients in which preoperative biopsy specimens were negative for neoplasia, whereas pCLE indicated the presence of malignancy. Also the median SNR derived from a region of interest in both normal and neoplastic epithelium was significantly different (lower in neoplasia), accounting for less broad intrinsic fluorescence intensity distribution in neoplastic tissue, which reflects different concentration of fluorophores following structural neoplastic rearrangement. A dark gray background with poor mucosal structure and large white streaks (vessels) was mainly seen in neoplastic strictures. On the contrary, a reticular pattern of different gray scales and villous structure without white streaks was seen in patients without neoplasia.

Peroral pancreatoscopy and pCLE has also been reported by the same group in a case of intraductal papillary mucinous neoplasm (IPMN). ${ }^{108}$ IPMN often goes unrecognized in patients with chronic pancreatitis, and its diagnosis is rather challenging. Based on the findings obtained with these two imaging methods, the diagnosis of IPMN was formed and was then confirmed by histology.

Loeser et al ${ }^{109}$ used pCLE in 14 patients with indeterminate biliary strictures together with standard biopsies and brushings. In parallel, they also examined rat bile ducts ex vivo using multiphoton microscopy to better understand the nature of the human bile duct structures visualized during confocal endomicroscopy. Of the 14 patients, six had a diagnosis of cancer. None of the criteria used to evaluate possible malignancy in the confocal images was found to be 
sufficiently specific for malignancy. An abnormal reticular network, which may reflect changes in lymphatic vessels, was never seen in benign strictures, and the authors proposed that in the absence of markers of potential malignancy, if a normal reticular pattern is visible then the diagnosis of malignancy is unlikely. The reticular pattern seen in normal tissue was believed to be a network of lymphatic vessels, as shown in multiphoton reconstructions of intact rat bile ducts and confirmed by special stains.

In an international multicenter study involving 102 patients with indeterminate pancreatobiliary strictures, pCLE outperformed tissue sampling in sensitivity $(98 \%$ versus $45 \%$ ), negative predictive value (97\% versus $69 \%$ ), and overall accuracy ( $81 \%$ versus $75 \%)$. However, pathology was unbeatable in specificity and positive predictive value. Delivery of the confocal miniprobe through a cholangioscope or via a catheter did not lead to significant differences in sensitivity and specificity. ${ }^{33}$

\section{Lower Gl tract}

Confocal imaging of a DALM in a patient with chronic ulcerative colitis has also been reported. ${ }^{110}$ Morphological characterization with pCLE was performed both over the lesion and adjacent inflamed mucosa, showing features suggestive of dysplasia and inflammation, respectively. The main aspect of inflamed mucosa consisted of dilation of crypt openings, irregular arrangement of crypts, crypt destruction and fusion, and crypt abscess. Dark mucin-depleted goblet cells and villiform epithelial digitations were recognized as dysplastic features in agreement with the Mainz classification for prediction of intraepithelial neoplasia. ${ }^{26}$

A prospective pilot study on 22 patients under surveillance for ulcerative colitis was conducted by van den Broek et $\mathrm{al}^{113}$ using NBI plus HDE followed by pCLE before taking targeted and random biopsies. Reasonable diagnostic accuracy was achieved, although movement artifacts significantly impaired the video quality.

Considering histology as gold standard, Buchner and Wallace $^{112}$ demonstrated that pCLE can accurately discriminate between hyperplastic and adenomatous polyps, and detect residual adenomatous tissue after EMR. They then compared pCLE with NBI and FICE, collectively named as virtual chromoendoscopy, in 119 polyps (81 neoplastic and 38 hyperplastic) from 75 patients. ${ }^{113}$ pCLE had higher sensitivity compared with virtual chromoendoscopy (91\% versus $77 \%$ ) for classification of colorectal polyps using histopathology as gold standard. In that study, HDE was used as the primary inspective technique. Prior to pCLE imaging, either FICE or NBI, depending on availability, were used after detection of a suspicious lesion. They also examined the learning curve faced by clinicians in correctly identifying benign and neoplastic colorectal lesions by using pCLE. ${ }^{114}$ Accuracy of image interpretation and acquisition increases with the number of images observed (up to $86 \%$ beyond 60 lesions).

In a recent prospective multicenter study, 92 patients who had their lesion removed by EMR in a previous colonoscopy were referred for follow-up colonoscopy within 1 year and inspection of EMR scars $(n=129)$ with NBI or FICE and pCLE to detect residual neoplasia. Accuracy of pCLE alone and in combination with NBI or FICE against histopathology as the gold standard was of $81 \%$ and $90 \%$, respectively; whereas the cumulative accuracy of virtual chromoendoscopy (NBI + FICE) alone was 77\%. ${ }^{34}$

In vivo characterization of 32 superficial colorectal neoplastic lesions with pCLE was performed by De Palma et al ${ }^{115}$ in 20 consecutive patients. pCLE presumptive diagnoses were compared with histopathology of resected lesions or targeted biopsies. The sensitivity and specificity of pCLE to differentiate neoplastic from hyperplastic lesions were $100 \%$ and $84.6 \%$, respectively.

The use of molecular biomarkers in combination with confocal endomicroscopy was first investigated by Hsiung et $\mathrm{al}^{83}$ to develop a fluorescent probe for detecting colon cancer. They identified a specific heptapeptide sequence, VRPMPLQ, which was conjugated with fluorescein and tested in patients undergoing colonoscopy. The fluorescein-conjugated peptide was administered topically and was found to bind more strongly to dysplastic cells than to adjacent normal cells, with $81 \%$ sensitivity and $82 \%$ specificity, respectively.

Wang et $\mathrm{al}^{27}$ conducted a pioneering observational study using pCLE in 54 patients undergoing bowel cancer screening colonoscopy, with the aim to track the uptake and distribution of fluorescein from the crypts to the lamina propria after topical administration. This contributed to further understanding the functional anatomy of the colonic glands in normal, hyperplastic, and adenomatous tissue in vivo. As with histology, the typical shape and size of glands for each tissue type is clearly discriminated, and there is correlation between tissue morphology and time of transit, with significantly longer time of passage through adenomatous mucosa ( $>5$ seconds) compared with hyperplastic or normal tissue. High diagnostic accuracy is achieved using the speed of absorption of fluorescein (contrast ratio) as a discriminant function to distinguish normal from diseased mucosa $(89 \%)$, 
hyperplasia from adenoma (96\%), and even tubular from villous adenoma (93\%).

Moderate to good interobserver agreement among three international experts and 76\% accuracy in diagnosis of neoplasia was achieved using pCLE in a study on 53 patients with 75 colorectal lesions, 50 of which were neoplastic. ${ }^{116}$ The authors concluded that current accuracy and interobserver agreement do not yet support routine clinical use in screening or surveillance colonoscopy.

\section{EC}

EC (Olympus Corporation) is a novel imaging technique, enabling microscopic imaging of the GI mucosal surface with a magnification of up to $\times 1,400 .{ }^{28} \mathrm{EC}$ is based on a contact light microscope which enables real-time visualization of cellular structures of the superficial epithelial layer in a plane parallel to the mucosal surface. Cytological and architectural features, such as the size and shape of cells, nuclei, and the nucleus to cytoplasm ratio, can be assessed. The technique uses a fixed-focus, high-power objective lens that projects highly magnified images onto a $\mathrm{CCD}$ at a rate of 30 frames per second. ${ }^{117}$

As for CLE, two types of EC systems are currently available on the market. A probe-based handheld miniprobe $(\mathrm{pEC})$, providing magnification of up to $\times 570$ and $\times 1,400$, which can be passed through the working channel of a conventional endoscope, and a system integrated into the distal tip of an endoscope (iEC), providing magnification of up to $\times 580$.

FOVs are $300 \mu \mathrm{m} \times 300 \mu \mathrm{m}, 120 \mu \mathrm{m} \times 120 \mu \mathrm{m}$, and $400 \mu \mathrm{m} \times 400 \mu \mathrm{m}$ for $\times 570 \mathrm{pEC}, \times 1,400 \mathrm{pEC}$, and $\times 580 \mathrm{iEC}$, respectively. The axial resolution varies from $0-50 \mu \mathrm{m}$, and the lateral resolution from $1.7-4.0 \mu \mathrm{m}$.

Using both systems, contact with the tissue surface is necessary for imaging. EC requires preparation of the mucosal layer with absorptive contrast agents like methylene blue or toluidine blue. ${ }^{28}$ Prior to imaging and tissue staining the mucosal surface must be treated with a mucolytic to remove excess mucous. Repeat staining is often needed after $\sim 5$ minutes of imaging.

\section{Clinical experience}

Promising initial results, primarily in identifying and discriminating neoplastic from non-neoplastic tissue, have been shown in a few prospective studies. ${ }^{117-120}$ Notably, EC is able to detect dysplasia in aberrant crypt foci of normal colon mucosa surrounding cancer, ${ }^{118}$ and discriminate invasive colon cancers from adenomatous polyps. ${ }^{120}$ In contrast, only a limited role has been found in detecting and predicting early esophageal squamous cell carcinoma. ${ }^{121}$ The potential of EC for the in vivo characterization of duodenal mucosa in coeliac disease has also been reported. ${ }^{122}$

Nevertheless, there is currently a paucity of interest and research on EC, possibly due to the requirement of topical staining, the relative lack of axial discrimination, and the low resolution images compared with other microscopy techniques such as CLE.

\section{Future potential optical imaging modalities}

Future prospects in endoscopic imaging include optical coherence tomography, ${ }^{123-125}$ multiphoton microscopy, ${ }^{126-131}$ second harmonic generation imaging, ${ }^{131,132}$ Raman endoscopy, ${ }^{133-135}$ coherent anti-Stokes Raman scattering microscopy, ${ }^{136-138}$ and FLIM. ${ }^{139-142}$

Studies with endoscopically compatible fiber-optic probes or prototype endoscopes are under way for validation of preliminary results. However, there is still a significant amount of technological development and clinical study required before they can become clinically viable methods.

\section{Conclusion}

Recent advances in endoscopy constitute an unprecedented leap forward in basic and clinical research for both patients and clinicians. However, the full adoption of any of these techniques in clinical practice still requires further extensive evaluation. For instance, especially in patients with dysplasia and early cancers, the objectivity and inter-rater reliability for each of these techniques have not been well studied, and this clearly affects their still low perceived clinical utility and acceptance. Future work could be directed toward the integration of analytical techniques such as Raman spectroscopy $^{137}$ or fluorescence lifetime spectroscopy ${ }^{143,144}$ in conventional accessory devices such as biopsy forceps or snares that could be operated in conjunction with advanced imaging techniques and potentially offer an objective complement to established wide-field image-enhanced techniques such as HDWLE, NBI, or AFI, which still suffer from operator-subjectivity and poor specificity. ${ }^{75-77,135,145-146} \mathrm{In}$ addition, these techniques can only infer structural aspects and do not provide functional information about the tissue. It is still unknown which approach or combination of techniques offers the best potential. The optimal method will probably entail the combination of a wide-field overview technique with an optical microscopy method. In this respect, the challenging combination of AFI and CLE seems promising, and further research is awaited. 
One optical technology potentially capable of this is FLIM. ${ }^{147}$ A FLIM scanning confocal endomicroscope design, ${ }^{35,148,149}$ and a wide-field FLIM endoscope probe ${ }^{150}$ have recently been proposed, and current efforts are directed to implement and validate this technology for modern endoscopy.

\section{Acknowledgments}

This work was supported by the UK Engineering and Physical Sciences Research Council (EPSRC, grant reference: EP/ F040202/1). Dr Sergio Coda acknowledges an EPSRC doctoral prize fellowship (EP/K502856/1). The authors thank Professor Paul French, Professor Gordon Stamp and Dr Chris Dunsby for their invaluable supervision, advice and support. The video abstract was filmed and edited by John Conway.

\section{Disclosure}

The authors report no conflicts of interest in this work.

\section{References}

1. Hellier MD, Williams JG. The burden of gastrointestinal disease: implications for the provision of care in the UK. Gut. 2007;56(2): $165-166$.

2. Lambert R, Saito H, Saito Y. High-resolution endoscopy and early gastrointestinal cancer...dawn in the East. Endoscopy. 2007;39(3): 232-237.

3. Heitmiller RF, Redmond M, Hamilton SR. Barrett's esophagus with high-grade dysplasia. An indication for prophylactic esophagectomy. Ann Surg. 1996;224(1):66-71.

4. Falk GW, Rice TW, Goldblum JR, Richter JE. Jumbo biopsy forceps protocol still misses unsuspected cancer in Barrett's esophagus with high-grade dysplasia. Gastrointest Endosc. 1999;49(2):170-176.

5. Tschanz ER. Do $40 \%$ of patients resected for Barrett esophagus with high-grade dysplasia have unsuspected adenocarcinoma? Arch Pathol Lab Med. 2005;129(2):177-180.

6. Axon A. Symptoms and diagnosis of gastric cancer at early curable stage. Best Pract Res Clin Gastroenterol. 2006;20(4):697-708.

7. Rex DK, Cutler CS, Lemmel GT, et al. Colonoscopic miss rates of adenomas determined by back-to-back colonoscopies. Gastroenterology. 1997;112(1):24-28.

8. van Rijn JC, Reitsma JB, Stoker J, Bossuyt PM, van Deventer SJ, Dekker E. Polyp miss rate determined by tandem colonoscopy: a systematic review. Am J Gastroenterol. 2006;101(2):343-350.

9. Rabeneck L, Paszat LF, Hilsden RJ, et al. Bleeding and perforation after outpatient colonoscopy and their risk factors in usual clinical practice. Gastroenterology. 2008;135(6):1899-1906, 1906. e1.

10. Thiis-Evensen E, Hoff GS, Sauar J, Langmark F, Majak BM, Vatn MH. Population-based surveillance by colonoscopy: effect on the incidence of colorectal cancer. Telemark Polyp Study I. Scand J Gastroenterol. 1999;34(4):414-420.

11. Leung K, Pinsky P, Laiyemo AO, Lanza E, Schatzkin A, Schoen RE. Ongoing colorectal cancer risk despite surveillance colonoscopy: the Polyp Prevention Trial Continued Follow-up Study. Gastrointest Endosc. 2010;71(1):111-117.

12. Shimoda T, Ikegami M, Fujisaki J, Matsui T, Aizawa S, Ishikawa E. Early colorectal carcinoma with special reference to its development de novo. Cancer. 1989;64(5):1138-1146.

13. Pinsky PF, Fleshman J, Mutch M, et al. One year recurrence of aberrant crypt foci. Cancer Prev Res (Phila). 2010;3(7):839-843.

14. Morson BC. Evolution of cancer of the colon and rectum. Cancer. 1974;34(Suppl 3):845-849.
15. Hurlstone DP, Cross SS, Adam I, et al. A prospective clinicopathological and endoscopic evaluation of flat and depressed colorectal lesions in the United Kingdom. Am J Gastroenterol. 2003;98(11):2543-2549.

16. Cairns SR, Scholefield JH, Steele RJ, et al. Guidelines for colorectal cancer screening and surveillance in moderate and high risk groups (update from 2002). Gut. 2010;59(5):666-689.

17. Itzkowitz S, Ullman T. The world isn't flat. Gastrointest Endosc. 2004;60(3):426-427.

18. Rex DK, Helbig CC. High yields of small and flat adenomas with high-definition colonoscopes using either white light or narrow band imaging. Gastroenterology. 2007;133(1):42-47.

19. Adler A, Aschenbeck J, Yenerim T, et al. Narrow-band versus whitelight high definition television endoscopic imaging for screening colonoscopy: a prospective randomized trial. Gastroenterology. 2009;136(2):410-416. e411; quiz 715.

20. Buchner A. High-definition colonoscopy detects colorectal polyps at a higher rate than standard white-light colonoscopy. Clin Gastroenterol Hepatol. 2010;8(4):364-370.

21. Kudo S, Tamura S, Nakajima T, Yamano H, Kusaka H, Watanabe H. Diagnosis of colorectal tumorous lesions by magnifying endoscopy. Gastrointest Endosc. 1996;44(1):8-14.

22. Gono K, Obi T, Yamaguchi M, et al. Appearance of enhanced tissue features in narrow-band endoscopic imaging. J Biomed Opt. 2004;9(3): 568-577.

23. Pohl J, May A, Rabenstein T, Pech O, Ell C. Computed virtual chromoendoscopy: a new tool for enhancing tissue surface structures. Endoscopy. 2007;39(1):80-83.

24. Hoffman A, Kagel C, Goetz M, et al. Recognition and characterization of small colonic neoplasia with high-definition colonoscopy using i-Scan is as precise as chromoendoscopy. Dig Liver Dis. 2010;42(1): $45-50$.

25. Nakaniwa N, Namihisa A, Ogihara T, et al. Newly developed autofluorescence imaging videoscope system for the detection of colonic neoplasms. Dig Endosc. 2005;17(3):235-240.

26. Kiesslich R, Burg J, Vieth M, et al. Confocal laser endoscopy for diagnosing intraepithelial neoplasias and colorectal cancer in vivo. Gastroenterology. 2004;127(3):706-713.

27. Wang TD, Friedland S, Sahbaie P, et al. Functional imaging of colonic mucosa with a fibered confocal microscope for real-time in vivo pathology. Clin Gastroenterol Hepatol. 2007;5(11):1300-1305.

28. Kwon RS, Wong Kee Song LM, Adler DG, et al. Endocytoscopy. Gastrointest Endosc. 2009;70(4):610-613.

29. Meining A, Saur D, Bajbouj M, et al. In vivo histopathology for detection of gastrointestinal neoplasia with a portable, confocal miniprobe: an examiner blinded analysis. Clin Gastroenterol Hepatol. 2007;5(11): 1261-1267.

30. Wallace MB, Sharma P, Lightdale C, et al. Preliminary accuracy and interobserver agreement for the detection of intraepithelial neoplasia in Barrett's esophagus with probe-based confocal laser endomicroscopy. Gastrointest Endosc. 2010;72(1):19-24.

31. Bajbouj M, Vieth M, Rösch T, et al. Probe-based confocal laser endomicroscopy compared with standard four-quadrant biopsy for evaluation of neoplasia in Barrett's esophagus. Endoscopy. 2010;42(06): 435-440.

32. Sharma P, Meining AR, Coron E, et al. Real-time increased detection of neoplastic tissue in Barrett's esophagus with probe-based confocal laser endomicroscopy: final results of an international multicenter, prospective, randomized, controlled trial. Gastrointest Endosc. 2011;74(3): 465-472.

33. Meining A, Chen YK, Pleskow D, et al. Direct visualization of indeterminate pancreaticobiliary strictures with probe-based confocal laser endomicroscopy: a multicenter experience. Gastrointest Endosc. 2011;74(5):961-968.

34. Shahid MW, Buchner AM, Coron E, et al. Diagnostic accuracy of probe-based confocal laser endomicroscopy in detecting residual colorectal neoplasia after EMR: a prospective study. Gastrointest Endosc. 2012;75(3):525-533.

35. Kennedy GT, Manning HB, Elson DS, et al. A fluorescence lifetime imaging scanning confocal endomicroscope. J Biophotonics. 2010;3(1-2):103-107. 
36. Tajiri H, Niwa H. Proposal for a consensus terminology in endoscopy: how should different endoscopic imaging techniques be grouped and defined? Endoscopy. 2008;40(9):775-778.

37. Dawsey SM, Fleischer DE, Wang GQ, et al. Mucosal iodine staining improves endoscopic visualization of squamous dysplasia and squamous cell carcinoma of the esophagus in Linxian, China. Cancer. 1998;83(2): 220-231.

38. Inoue H, Rey JF, Lightdale C. Lugol chromoendoscopy for esophageal squamous cell cancer. Endoscopy. 2001;33(1):75-79.

39. Meyer V, Burtin P, Bour B, et al. Endoscopic detection of early esophageal cancer in a high-risk population: does Lugol staining improve videoendoscopy? Gastrointest Endosc. 1997;45(6):480-484.

40. Committee AT, Wong Kee Song LM, Adler DG, et al. Chromoendoscopy. Gastrointest Endosc. 2007;66(4):639-649.

41. Meining A, Rosch T, Kiesslich R, Muders M, Sax F, Heldwein W. Inter- and intra-observer variability of magnification chromoendoscopy for detecting specialized intestinal metaplasia at the gastroesophageal junction. Endoscopy. 2004;36(2):160-164

42. Canto MI, Setrakian S, Willis JE, Chak A, Petras RE, Sivak MV. Methylene blue staining of dysplastic and nondysplastic Barrett's esophagus: an in vivo and ex vivo study. Endoscopy. 2001;33(5): 391-400.

43. Canto MI, Setrakian S, Willis J, et al. Methylene blue-directed biopsies improve detection of intestinal metaplasia and dysplasia in Barrett's esophagus. Gastrointest Endosc. 2000;51(5):560-568

44. Ragunath K, Krasner N, Raman VS, Haqqani MT, Cheung WY. A randomized, prospective cross-over trial comparing methylene blue-directed biopsy and conventional random biopsy for detecting intestinal metaplasia and dysplasia in Barrett's esophagus. Endoscopy. 2003;35(12):998-1003.

45. Egger K, Werner M, Meining A, et al. Biopsy surveillance is still necessary in patients with Barrett's oesophagus despite new endoscopic imaging techniques. Gut. 2003;52(1):18-23.

46. Lim CH, Rotimi O, Dexter SP, Axon AT. Randomized crossover study that used methylene blue or random 4-quadrant biopsy for the diagnosis of dysplasia in Barrett's esophagus. Gastrointest Endosc. 2006;64(2): 195-199.

47. Endo T, Awakawa T, Takahashi H, et al. Classification of Barrett's epithelium by magnifying endoscopy. Gastrointest Endosc. 2002;55(6): 641-647.

48. Sharma P, Weston AP, Topalovski M, Cherian R, Bhattacharyya A, Sampliner RE. Magnification chromoendoscopy for the detection of intestinal metaplasia and dysplasia in Barrett's oesophagus. Gut 2003;52(1):24-27.

49. Guelrud M, Herrera I, Essenfeld H, Castro J. Enhanced magnification endoscopy: a new technique to identify specialized intestinal metaplasia in Barrett's esophagus. Gastrointest Endosc. 2001;53(6): 559-565.

50. Dinis-Ribeiro M, da Costa-Pereira A, Lopes C, et al. Magnification chromoendoscopy for the diagnosis of gastric intestinal metaplasia and dysplasia. Gastrointest Endosc. 2003;57(4):498-504.

51. Kato S, Fujii T, Koba I, et al. Assessment of colorectal lesions using magnifying colonoscopy and mucosal dye spraying: can significant lesions be distinguished? Endoscopy. 2001;33(4): 306-310.

52. Kudo S, Tamura S, Hirota S, et al. The problem of de novo colorectal carcinoma. Eur J Cancer. 1995;31(7-8):1118-1120.

53. Kiesslich R, Jung M. Magnification endoscopy: does it improve mucosal surface analysis for the diagnosis of gastrointestinal neoplasias? Endoscopy. 2002;34(10):819-822.

54. Le Rhun M, Coron E, Parlier D, et al. High resolution colonoscopy with chromoscopy versus standard colonoscopy for the detection of colonic neoplasia: a randomized study. Clin Gastroenterol Hepatol. 2006;4(3):349-354.

55. Hurlstone DP, Cross SS, Slater R, Sanders DS, Brown S. Detecting diminutive colorectal lesions at colonoscopy: a randomised controlled trial of pan-colonic versus targeted chromoscopy. Gut. 2004;53(3): 376-380.
56. Brooker JC, Saunders BP, Shah SG, et al. Total colonic dye-spray increases the detection of diminutive adenomas during routine colonoscopy: a randomized controlled trial. Gastrointest Endosc. 2002;56(3):333-338.

57. Zonios G, Perelman LT, Backman V, Manoharan R, Fitzmaurice M, Van Dam J, Feld MS. Diffuse reflectance spectroscopy of human adenomatous colon polyps in vivo. Appl Opt. 1999; 38(31):6628-6637.

58. Gono K, Yamazaki K, Doguchi N, et al. Endoscopic observation of tissue by narrowband illumination. Optical Rev. 2003;10(4): 211-215.

59. Kara MA, Peters FP, Rosmolen WD, et al. High-resolution endoscopy plus chromoendoscopy or narrow-band imaging in Barrett's esophagus: a prospective randomized crossover study. Endoscopy. 2005;37(10): 929-936.

60. Wolfsen HC, Crook JE, Krishna M, et al. Prospective, controlled tandem endoscopy study of narrow band imaging for dysplasia detection in Barrett's esophagus. Gastroenterology. 2008;135(1):24-31.

61. Sharma P, Hawes RH, Bansal A, et al. Standard endoscopy with random biopsies versus narrow band imaging targeted biopsies in Barrett's oesophagus: a prospective, international, randomised controlled trial. Gut. 2013;62(1):15-21.

62. Adler A, Pohl H, Papanikolaou IS, et al. A prospective randomised study on narrow-band imaging versus conventional colonoscopy for adenoma detection: does narrow-band imaging induce a learning effect? Gut. 2008;57(1):59-64

63. East JE, Suzuki N, Bassett P, et al. Narrow band imaging with magnification for the characterization of small and diminutive colonic polyps: pit pattern and vascular pattern intensity. Endoscopy. 2008;40(10):811-817.

64. East JE, Suzuki N, Saunders BP. Comparison of magnified pit pattern interpretation with narrow band imaging versus chromoendoscopy for diminutive colonic polyps: a pilot study. Gastrointest Endosc. 2007;66(2):310-316.

65. East JE, Suzuki N, Stavrinidis M, Guenther T, Thomas HJ, Saunders BP. Narrow band imaging for colonoscopic surveillance in hereditary nonpolyposis colorectal cancer. Gut. 2008;57(1):65-70.

66. East JE, Tan EK, Bergman JJ, Saunders BP, Tekkis PP. Meta-analysis: narrow band imaging for lesion characterization in the colon, oesophagus, duodenal ampulla and lung. Aliment Pharmacol Ther. 2008;28(7): 854-867.

67. Dekker E, van den Broek FJ, Reitsma JB, et al. Narrow-band imaging compared with conventional colonoscopy for the detection of dysplasia in patients with longstanding ulcerative colitis. Endoscopy. 2007;39(3):216-221.

68. Tanaka S, Sano Y. Aim to unify the narrow band imaging (NBI) magnifying classification for colorectal tumors: current status in Japan from a summary of the consensus symposium in the 79th Annual Meeting of the Japan Gastroenterological Endoscopy Society. Dig Endosc. 2011; 23 Suppl 1:131-139.

69. Miyake Y, Sekiya T, Hara T. A new spectrophotometer for measuring the spectral reflectance of gastric mucous membrane. J Photogr Sci. 1989;37(3-4):134-138.

70. Miyake Y, Nakaguchi T, Tsumura N, Yamataka S. Development of new electronic endoscopes using the spectral images of an internal organ. Paper presented at: Proceedings of the IS\&T/SID's Thirteen Color Imaging Conference; Scottsdale, AZ, USA: 2005.

71. Pohl J, May A, Rabenstein T, et al. Comparison of computed virtual chromoendoscopy and conventional chromoendoscopy with acetic acid for detection of neoplasia in Barrett's esophagus. Endoscopy 2007;39(7):594-598.

72. Osawa H, Yamamoto H, Yamada N, et al. Diagnosis of endoscopic Barrett's esophagus by transnasal flexible spectral imaging color enhancement. J Gastroenterol. 2009;44(11):1125-1132.

73. Neumann H, Fry LC, Bellutti M, Malfertheiner P, Monkemuller K. Double-balloon enteroscopy-assisted virtual chromoendoscopy for small-bowel disorders: a case series. Endoscopy. 2009;41(5) $468-471$. 
74. Basford PJ, Longcroft-Wheaton G, Higgins B, Bhandari P. Highdefinition endoscopy with i-Scan for evaluation of small colon polyps: the HiSCOPE study. Gastrointest Endosc. 2014;79(1): 111-118.

75. Wong Kee Song L-M, Banerjee S, Desilets D, et al. Autofluorescence imaging. Gastrointest Endosc. 2011;73(4):647-650.

76. van den Broek FJC, Fockens P, van Eeden S, et al. Endoscopic tri-modal imaging for surveillance in ulcerative colitis: randomised comparison of high-resolution endoscopy and autofluorescence imaging for neoplasia detection; and evaluation of narrow-band imaging for classification of lesions. Gut. 2008;57(8):1083-1089.

77. Falk GW. Autofluorescence endoscopy. Gastrointest Endosc Clin NAm. 2009;19(2):209-220.

78. Borovicka J, Fischer J, Neuweiler J, et al. Autofluorescence endoscopy in surveillance of Barrett's esophagus: a multicenter randomized trial on diagnostic efficacy. Endoscopy. 2006;38(09):867-872.

79. Curvers WL, Singh R, Song LM, et al. Endoscopic tri-modal imaging for detection of early neoplasia in Barrett's oesophagus: a multi-centre feasibility study using high-resolution endoscopy, autofluorescence imaging and narrow band imaging incorporated in one endoscopy system. Gut. 2008;57(2):167-172.

80. Thomas T, Singh R, Ragunath K. Trimodal imaging-assisted endoscopic mucosal resection of early Barrett's neoplasia. Surg Endosc. 2009;23(7):1609-1613.

81. Fuster MM, Esko JD. The sweet and sour of cancer: glycans as novel therapeutic targets. Nat Rev Cancer. 2005;5(7):526-542.

82. Laughlin ST, Bertozzi CR. Imaging the glycome. Proc Natl Acad Sci US A. 2009;106(1):12-17.

83. Hsiung P-L, Hardy J, Friedland S, et al. Detection of colonic dysplasia in vivo using a targeted heptapeptide and confocal microendoscopy. Nat Med. 2008;14(4):454-458.

84. Li M, Anastassiades CP, Joshi B, et al. Affinity peptide for targeted detection of dysplasia in Barrett's esophagus. Gastroenterology. 2010;139(5):1472-1480.

85. Bird-Lieberman EL, Neves AA, Lao-Sirieix P, et al. Molecular imaging using fluorescent lectins permits rapid endoscopic identification of dysplasia in Barrett's esophagus. Nat Med. 2012;18(2):315-321.

86. Kim WJ, Cho JY, Jeong SW, et al. Comparison of autofluorescence imaging endoscopic findings with pathologic findings after endoscopic submucosal dissection of gastric neoplasms. Gut Liver. 2008;2(3): 186-192.

87. van den Broek FJC, Fockens P, van Eeden S, et al. Clinical evaluation of endoscopic trimodal imaging for the detection and differentiation of colonic polyps. Clin Gastroenterol Hepatol. 2009;7(3):288-295.

88. Kuiper T, van den Broek FJ, Naber AH, et al. Endoscopic trimodal imaging detects colonic neoplasia as well as standard video endoscopy. Gastroenterology. 2011;140(7):1887-1894.

89. Boparai KS, van den Broek FJ, van Eeden S, Fockens P, Dekker E. Hyperplastic polyposis syndrome: a pilot study for the differentiation of polyps by using high-resolution endoscopy, autofluorescence imaging, and narrow-band imaging. Gastrointest Endosc. 2009;70(5): 947-955.

90. Moriichi K, Fujiya M, Sato R, et al. Autofluorescence imaging and the quantitative intensity of fluorescence for evaluating the dysplastic grade of colonic neoplasms. Int J Colorectal Dis. 2012;27(3): $325-330$.

91. Ueno N, Fujiya M, Moriichi K, et al. Endosopic autofluorescence imaging is useful for the differential diagnosis of intestinal lymphomas resembling lymphoid hyperplasia. J Clin Gastroenterol. 2011;45(6): 507-513.

92. Minsky M, inventor; Minsky M, assignee. Microscopy apparatus. United States patent US3013467 A. December 19, 1961.

93. Minsky M. Memoir on inventing the confocal scanning microscope. Scanning. 1988;10(4):128-138.

94. Humphris J, Swartz D, Egan BJ, Leong RW. Status of confocal laser endomicroscopy in gastrointestinal disease. Trop Gastroenterol. 2012;33(1):9-20.
95. Committee AT, Kantsevoy SV, Adler DG, et al. Confocal laser endomicroscopy. Gastrointest Endosc. 2009;70(2):197-200.

96. Azar FS, Intes X. Translational Multimodality Optical Imaging. Boston: Artech House; 2008.

97. Goetz M, Kiesslich R. Advanced imaging of the gastrointestinal tract: research vs clinical tools? Curr Opin Gastroenterol. 2009;25(5): 412-421.

98. Polglase A, McLaren W, Skinner S, Kiesslich R, Neurath M, Delaney P. A fluorescence confocal endomicroscope for in vivo microscopy of the upper- and the lower-GI tract. Gastrointest Endosc. 2005;62:686-695.

99. Burleson GR, Caulfield MJ, Pollard M. Ozonation of mutagenic and carcinogenic polyaromatic amines and polyaromatic hydrocarbons in water. Cancer Res. 1979;39(6 Pt 1):2149-2154.

100. Becker V, von Delius S, Bajbouj M, Karagianni A, Schmid RM, Meining A. Intravenous application of fluorescein for confocal laser scanning microscopy: evaluation of contrast dynamics and image quality with increasing injection-to-imaging time. Gastrointest Endosc. 2008;68(2):319-323.

101. Kiesslich R, Neurath MF. Endomicroscopy is born - do we still need the pathologist? Gastrointest Endosc. 2007;66(1):150-153.

102. De Palma GD. Confocal laser endomicroscopy in the "in vivo" histological diagnosis of the gastrointestinal tract. World J Gastroenterol. 2009;15(46):5770-5775.

103. Nguyen NQ, Leong RWL. Current application of confocal endomicroscopy in gastrointestinal disorders. $J$ Gastroenterol Hepatol. 2008;23(10):1483-1491.

104. Kiesslich R, Gossner L, Goetz M, et al. In vivo histology of Barrett's esophagus and associated neoplasia by confocal laser endomicroscopy. Clin Gastroenterol Hepatol. 2006;4(8):979-987.

105. Neumann H, Vieth M, Raithel M, Mudter J, Kiesslich R, Neurath MF. Confocal laser endomicroscopy for the in vivo detection of intraepithelial neoplasia in Peutz-Jeghers polyps. Endoscopy. 2010; 42 Suppl 2:E139-E140.

106. Sanduleanu S, Driessen A, Gomez-Garcia E, Hameeteman W, de Bruine A, Masclee A. In vivo diagnosis and classification of colorectal neoplasia by chromoendoscopy-guided confocal laser endomicroscopy. Clin Gastroenterol Hepatol. 2010;8(4): 371-378.

107. Meining A, Frimberger E, Becker V, et al. Detection of cholangiocarcinoma in vivo using miniprobe-based confocal fluorescence microscopy. Clin Gastroenterol Hepatol. 2008;6(9):1057-1060.

108. Meining A, Phillip V, Gaa J, Prinz C, Schmid RM. Pancreaticoscopy with miniprobe-based confocal laser-scanning microscopy of an intraductal papillary mucinous neoplasm (with video). Gastrointest Endosc. 2009;69(6):1178-1180.

109. Loeser CS, Robert ME, Mennone A, Nathanson MH, Jamidar P. Confocal endomicroscopic examination of malignant biliary strictures and histologic correlation with lymphatics. J Clin Gastroenterol. 2011;45(3):246-252.

110. De Palma GD. In-vivo characterization of DALM in ulcerative colitis with high-resolution probe-based confocal laser endomicroscopy. World J Gastroenterol. 2011;17(5):677-680.

111. van den Broek FJC, van Es JA, van Eeden S, et al. Pilot study of probe-based confocal laser endomicroscopy during colonoscopic surveillance of patients with longstanding ulcerative colitis. Endoscopy. 2011;43(02):116-122.

112. Buchner AM, Wallace MB. Future expectations in digestive endoscopy: competition with other novel imaging techniques. Best Pract Res Clin Gastroenterol. 2008;22(5):971-987.

113. Buchner AM, Shahid MW, Heckman MG, et al. Comparison of probebased confocal laser endomicroscopy with virtual chromoendoscopy for classification of colon polyps. Gastroenterology. 2010;138(3): 834-842.

114. Buchner AM, Gomez V, Heckman MG, et al. The learning curve of in vivo probe-based confocal laser endomicroscopy for prediction of colorectal neoplasia. Gastrointest Endosc. 2011;73(3):556-560. 
115. De Palma GD, Staibano S, Siciliano S, et al. In vivo characterisation of superficial colorectal neoplastic lesions with high-resolution probe-based confocal laser endomicroscopy in combination with video-mosaicing: a feasibility study to enhance routine endoscopy. Dig Liver Dis. 2010;42(11):791-797.

116. Gómez V, Buchner AM, Dekker E, et al. Interobserver agreement and accuracy among international experts with probe-based confocal laser endomicroscopy in predicting colorectal neoplasia. Endoscopy. 2010;42(04):286-291.

117. Inoue H, Sasajima K, Kaga M, et al. Endoscopic in vivo evaluation of tissue atypia in the esophagus using a newly designed integrated endocytoscope: a pilot trial. Endoscopy. 2006;38(9):891-895.

118. Cipolletta L, Bianco MA, Rotondano G, et al. Endocytoscopy can identify dysplasia in aberrant crypt foci of the colorectum: a prospective in vivo study. Endoscopy. 2009;41(2):129-132.

119. Neumann H, Vieth M, Neurath MF. Image of the month. Endocytoscopy-based detection of focal high-grade intraepithelial neoplasia in colonic polyps. Clin Gastroenterol Hepatol. 2011; 9(2):e13.

120. Sasajima K, Kudo SE, Inoue H, et al. Real-time in vivo virtual histology of colorectal lesions when using the endocytoscopy system. Gastrointest Endosc. 2006;63(7):1010-1017.

121. Kumagai Y, Kawada K, Yamazaki S, et al. Endocytoscopic observation for esophageal squamous cell carcinoma: can biopsy histology be omitted? Dis Esophagus. 2009;22(6):505-512.

122. Pohl H, Rosch T, Tanczos BT, Rudolph B, Schluns K, Baumgart DC. Endocytoscopy for the detection of microstructural features in adult patients with celiac sprue: a prospective, blinded endocytoscopy-conventional histology correlation study. Gastrointest Endosc. 2009;70(5):933-941.

123. Tearney GJ, Brezinski ME, Bouma BE, et al. In vivo endoscopic optical biopsy with optical coherence tomography. Science. 1997;276(5321): 2037-2039

124. Tearney GJ, Brezinski ME, Southern JF, Bouma BE, Boppart SA, Fujimoto JG. Optical biopsy in human gastrointestinal tissue using optical coherence tomography. Am J Gastroenterol. 1997;92(10): 1800-1804.

125. Zhou C, Adler DC, Becker L, et al. Effective treatment of chronic radiation proctitis using radiofrequency ablation. Therap $A d v$ Gastroenterol. 2009;2(3):149-156.

126. Myaing MT, MacDonald DJ, Li X. Fiber-optic scanning two-photon fluorescence endoscope. Opt Lett. 2006;31(8):1076-1078.

127. Engelbrecht CJ, Johnston RS, Seibel EJ, Helmchen F. Ultra-compact fiber-optic two-photon microscope for functional fluorescence imaging in vivo. Opt Express. 2008;16(8):5556-5564.

128. Tang S, Jung W, McCormick D, et al. Design and implementation of fiber-based multiphoton endoscopy with microelectromechanical systems scanning. J Biomed Opt. 2009;14(3):034005.

129. Rivera DR, Brown CM, Ouzounov DG, et al. Compact and flexible raster scanning multiphoton endoscope capable of imaging unstained tissue. Proc Natl Acad Sci U S A. 2011;108(43):17598-17603.

130. Grosberg LE, Radosevich AJ, Asfaha S, Wang TC, Hillman EMC. Spectral characterization and unmixing of intrinsic contrast in intact normal and diseased gastric tissues using hyperspectral two-photon microscopy. PLoS One. 2011;6(5):e19925.

131. Schurmann S, Foersch S, Atreya R, et al. Label-free imaging of inflammatory bowel disease using multiphoton microscopy. Gastroenterology. 2013;145(3):514-516.

132. Campagnola P. Second harmonic generation imaging microscopy: applications to diseases diagnostics. Anal Chem. 2011;83(9): 3224-3231.
133. Bergholt MS, Zheng W, Lin K, et al. In vivo diagnosis of esophageal cancer using image-guided Raman endoscopy and biomolecular modeling. Technol Cancer Res Treat. 2011;10(2):103-112.

134. Shao X, Zheng W, Huang Z. Near-infrared autofluorescence spectroscopy for in vivo identification of hyperplastic and adenomatous polyps in the colon. Biosens Bioelectron. 2011;30(1): 118-122.

135. Almond LM, Hutchings J, Lloyd G, et al. Endoscopic Raman spectroscopy enables objective diagnosis of dysplasia in Barrett's esophagus. Gastrointest Endosc. 2014;79(1):37-45.

136. Krafft C, Ramoji AA, Bielecki C, et al. A comparative Raman and CARS imaging study of colon tissue. J Biophotonics. 2009;2(5): 303-312.

137. Légaré F, Evans CL, Ganikhanov F, Xie XS. Towards CARS Endoscopy. Opt Express. 2006;14(10):4427-4432.

138. Wang Z, Liu Y, Gao L, et al. Use of multimode optical fibers for fiber-based coherent anti-Stokes Raman scattering microendoscopy imaging. Opt Lett. 2011;36(15):2967-2969.

139. McGinty J, Galletly NP, Dunsby C, et al. Wide-field fluorescence lifetime imaging of cancer. Biomed Opt Express. 2010;1(2): 627-640.

140. Sun Y, Phipps J, Elson DS, et al. Fluorescence lifetime imaging microscopy: in vivo application to diagnosis of oral carcinoma. Opt Lett. 2009;34(13):2081-2083.

141. Sun Y, Hatami N, Yee M, et al. Fluorescence lifetime imaging microscopy for brain tumor image-guided surgery. J Biomed Opt. 2010;15(5):056022.

142. Coda S, Thompson AJ, Lenz MO, et al. Sa1609 fluorescence lifetime imaging and spectroscopy for label-free contrast of gastrointestinal diseases. Gastrointest Endosc. 2012;75(4):AB219-AB220.

143. Mycek M, Schomacker K, Nishioka N. Colonic polyp differentiation using time-resolved autofluorescence spectroscopy. Gastrointest Endosc. 1998;48(4):390-394.

144. Coda S, Thompson AJ, Kennedy GT, et al. Fluorescence lifetime spectroscopy of tissue autofluorescence in normal and diseased colon measured ex vivo using a fiber-optic probe. Biomed Opt Express. 2014;5(2):515-538.

145. Curvers W, Baak L, Kiesslich R, et al. Chromoendoscopy and narrow-band imaging compared with high-resolution magnification endoscopy in Barrett's esophagus. Gastroenterology. 2008;134(3): 670-679.

146. Sharma P, Bansal A, Mathur S, et al. The utility of a novel narrow band imaging endoscopy system in patients with Barrett's esophagus. Gastrointest Endosc. 2006;64(2):167-175

147. Marcu L. Fluorescence lifetime techniques in medical applications. Ann Biomed Eng. 2012;40(2):304-331.

148. Kumar S, Alibhai D, Margineanu A, et al. FLIM FRET technology for drug discovery: automated multiwell-plate high-content analysis, multiplexed readouts and application in situ. Chemphyschem. 2011;12(3):609-626.

149. Kennedy GT, Coda S, Thompson AJ, et al. Fluorescence lifetime imaging endoscopy. Proc Spie. 2011;7893.

150. Sun YH, Phipps JE, Meier J, et al. Endoscopic fluorescence lifetime imaging for in vivo intraoperative diagnosis of oral carcinoma. Microsc Microanal. 2013;19(4):791-798.

151. Kumar S. Development of Multidimensional Fluorescence Imaging Technology with a View towards the Imaging of Signalling at the Immunological Synapse [doctoral thesis]. London: Chemical Biology Centre, Department of Chemistry, Imperial College London; 2010. 


\section{Publish your work in this journal}

Clinical and Experimental Gastroenterology is an international, peerreviewed, open access journal, publishing all aspects of gastroenterology in the clinic and laboratory, including: Pathology, pathophysiology of gastrointestinal disease; Investigation and treatment of gastointestinal disease; Pharmacology of drugs used in the alimentary tract;
Immunology/genetics/genomics related to gastrointestinal disease. This journal is indexed on CAS. The manuscript management system is completely online and includes a very quick and fair peer-review system. Visit http://www.dovepress.com/testimonials.php to read real quotes from published authors.

Submit your manuscript here: http://www.dovepress.com/clinical-and-experimental-gastroenterology-journal 